\title{
Guerra Fria na Região Amazônica: um estudo da Missão Venturini ao Suriname (1983)
}

\author{
Cold war in the Amazon Region: a study of Venturini's \\ mission to the Suriname (1983)
}

CARLOS FEDERICO DOMÍNGUEZ AVILA*

Rev. Bras. Polít. Int. 54 (1): 7-28 [2011]

\section{Introdução}

Em 11 de abril de 1983, o governo brasileiro, então comandado pelo general João Figueiredo, determinou o envio de uma missão de alto nível ao Suriname para oferecer a intensificação das relações bilaterais mediante um expressivo pacote de assistência política, militar e econômica ao regime do comandante Desiré Delano Bouterse. A missão visitou Paramaribo entre 15 e 17 de abril de 1983 e foi liderada pelo general Danilo Venturini, na época o secretário-geral do Conselho de Segurança Nacional do Brasil. A situação política e social interna do Suriname era altamente relevante para o governo brasileiro em função de consideraçôes geopolíticas, inclusive no contexto do conflito Leste-Oeste devido à crescente aproximação do Suriname ao bloco socialista.

A opção sul-americana proposta pelo regime burocrático autoritário brasileiro ao governo do comandante Bouterse significava, na prática, a implementação de uma estratégia de virtual cooptação das autoridades de Paramaribo - que na época experimentavam um severo processo de distanciamento com relação à Holanda e aos Estados Unidos. Em troca, as autoridades da antiga colônia holandesa deveriam reconhecer a liderança brasileira na região, afastar-se da órbita soviético-cubana e tentar uma reconciliação com as potências ocidentais tradicionais.

Nessa linha, o presente artigo explora as relaçōes bilaterais construídas entre o Brasil e o Suriname durante a primeira metade da década de 1980. O artigo é resultado de pesquisa com fontes primárias. Foi consultada documentação brasileira resguardada tanto no Arquivo Histórico do Ministério das Relações Exteriores quanto no Arquivo Nacional. Ao todo, são mais de 300 documentos - inclusive ofícios, telegramas e memorandos considerados confidenciais e secretos - produzidos por autoridades políticas, militares e diplomáticas diretamente vinculadas ao processo

\footnotetext{
* Doutor em História das Relaçôes Internacionais pela Universidade de Brasília, docente e pesquisador do Mestrado em Ciência Política do Centro Universitário Unieuro (cdominguez_unieuro@yahoo.com.br).
} 
de formulação e implementação da política para o Suriname. Cumpre adiantar que a documentação consultada também se caracteriza pela sua consistência, coerência (interna e externa), equilíbrio, pragmatismo burocrático, e aderência ou pertinência à temática ora considerada.

\section{O golpe dos sargentos e a revolução surinamesa}

Em 25 de fevereiro de 1980, um comando de 16 militares subalternos dirigidos pelo então sargento-maior Desiré Delano Bouterse - logrou controlar os quartéis de Paramaribo e forçar a demissão do primeiro-ministro Henck Arron e do alto mando militar e policial do país (SINGH, 2007). Sem uma ideologia preestabelecida ou consistente, o golpe dos sargentos justificou a ação de força propugnando o combate à corrupção administrativa, uma postura de maior autonomia em relação à Holanda, e principalmente reivindicações classistas, salariais e profissionais. Alguns sargentos - especialmente Badresein Sital - afirmaram que o golpe deveria ser considerado, na verdade, como o início de uma revolução social e política no país.

Vitorioso o movimento, os sargentos instituíram um Conselho Nacional Militar, com objetivo de fiscalizar o governo civil - que continuou sendo nominalmente dirigido pelo presidente Johan Ferrier e acompanhado pelo novo primeiro-ministro Henck Chin A Sen. Na realidade, o poder político na antiga democracia parlamentar surinamesa deslocou-se para o colegiado militar, cujas determinações tornaram-se obrigatórias. Todavia, o autoascendido comandante Bouterse erigiu-se como o verdadeiro dirigente político-militar do país. Pouco adepto a posturas ideologicamente firmes ou consistentes, Bouterse demonstrou possuir um agudo sentido pragmático, que lhe garantiu sua sobrevivência política. Apreciado por alguns e questionado por outros, o caudilho da revolução surinamesa não deixou de utilizar políticas populistas, personalistas, paternalistas, anticolonialistas e, às vezes, autoritárias ou radicais. De pouco carisma, com limitado apoio popular - especialmente após o massacre de dezembro de 1982 -, submetido a crescente isolamento doméstico e internacional, e sem experiência na administração pública, o chefe das forças armadas do Suriname terminou adotando slogans de esquerda - e despertando preocupaçôes inclusive no seio do governo burocrático autoritário predominante em Brasília.

Assim, a relativa calma e estabilidade democrática do Suriname vigente desde sua independência - em 1975 - foi substituída por crescente autoritarismo, polarização ideológica, personalismo e violência política. Em agosto de 1980, no meio de um suposto complô da esquerda, foi demitido o presidente Ferrier, desativado o parlamento, suspensa a Constituição e decretado o estado de emergência, que vigorou até 1984. A rejeição dos militares aos denominados partidos de orientação étnica - especialmente ao Partido Nacional do Suriname e ao Partido da Reforma Progressista - resultou na convergência com dois 
pequenos partidos de esquerda: a União Progressista dos Trabalhadores Pobres (Progressieve Arbeiders en Landbouwers Unie - PALU, de orientação nacionalista e dirigido por Errol Alibux e Winston Caldeira) e o Partido Revolucionário do Povo (Revolutionaire Volkspartij - RVP, de orientação castrista e dirigido por Michael Naarendorp). Gradualmente, os militantes do PALU e do RVP assumiram importantes cargos ministeriais no governo revolucionário.

Cumpre acrescentar que a retórica revolucionária do governo surinamês contrastava com as reivindicações de muitas das principais entidades classistas do país, particularmente com as organizaçôes empresariais, religiosas, sindicalistas e com setores moderados (e conservadores) das forças armadas. De modo geral, esses setores da sociedade exigiam um pronto retorno à ordem constitucional e à democracia parlamentarista. Observe-se que a demissão do moderado premier Henck Chin A Sen, em fevereiro de 1982, foi provocada pelas divergências com Bouterse sobre a necessidade de acelerar a abertura democrática e a eventual realização de eleições em dezembro do mesmo ano. Chin A Sen foi substituído pelo juiz Ramdat Misier no cargo de presidente da República. Contudo, o poder político real continuou concentrado na figura do comandante Bouterse, que demonstrou crescente simpatia pelo modelo impulsionado na ilha-Estado de Granada pelo primeiro-ministro Maurice Bishop e seu New Jewel Movement (DOMÍNGUEZ AVILA, 2008). A admiração e identificação de Bouterse pela experiência revolucionária granadina resultaram num convite para que o primeiroministro Bishop visitasse Paramaribo, em outubro de 1982.

A visita de Bishop ao Suriname redundou em um desastre para Bouterse. $\mathrm{Na}$ ocasião, em comício paralelo ao organizado pelo governo, o líder sindicalista Cyril Dahl criticou duramente as tendências autoritárias predominantes no Suriname e exigiu a realização imediata de eleições, o retorno dos militares aos quartéis, o fim do estado de emergência e das detenções arbitrárias, a elaboração de uma nova lei de partidos políticos, o fim da censura e o respeito aos direitos humanos dos surinamenses. As demandas do líder sindical tiveram ressonância na sociedade particularmente nos setores liberais, nas classes médias e nos profissionais. Nos primeiros dias de novembro iniciaram-se negociaçōes entre militares moderados encabeçados pelo major Roy Horb - segundo homem do regime - e a denominada Associação pela Democracia.

Contudo, Bouterse recusou-se a aceitar as condições impostas para a redemocratização, propondo suas próprias ideias sobre a constituição de uma democracia popular - em substituição da democracia parlamentarista anteriormente vigente no país. E diante do impasse político, Bouterse e seguidores - especialmente a ala revolucionária do governo - optaram pela radicalização e a violenta repressão da oposição liberal-democrática, que culminou com o denominado massacre de 8-9 de dezembro de 1982. Na trágica jornada, quinze importantes lideranças oposicionistas - advogados, sindicalistas, jornalistas, acadêmicos, militares - foram brutalmente torturados e assassinados. Também foram destruídas as instalações 
físicas da principal central sindical do país - Moederbond - e várias emissoras de rádio e televisão, bem como as sedes de jornais oposicionistas. Para o embaixador brasileiro em Paramaribo, Nestor dos Santos Lima, tratou-se de um virtual golpe preventivo "para liquidar de um só golpe todos os líderes potenciais do país em todos os setores, decapitando, assim, por um tempo, qualquer veleidade de reação do país à progressiva cubanização do Suriname."1

O furor repressivo do regime revolucionário continuou vigorando até o mês de fevereiro de 1983, inclusive com o expurgo de elementos moderados das forças armadas - principalmente de militares vinculados ao major Roy Horb, que terminou sendo assassinado em prisão em 3 de fevereiro de 1983 -, com imposição de rígida censura de imprensa e com a instalação de um virtual estado policial no país. ${ }^{2}$ A tradicionalmente pacífica e paroquial sociedade surinamesa - que na época era integrada por 350 mil pessoas - reagiu estarrecida e perplexa diante da violenta ação do estado revolucionário. A limitada legitimidade popular do regime ficou claramente em dúvida, devido à repulsa cidadã que lhe retirou - durante bastante tempo - qualquer base de sustentação político-democrática. ${ }^{3}$

Para os diplomatas brasileiros, o isolamento e o pragmatismo de Bouterse eram evidentes. "Evidencia-se, cada vez mais, que Bouterse tem agido, acima de qualquer concepção política, para garantir sua própria sobrevivência no poder. Nesse contexto, é impressão generalizada que Bouterse se apoiará sobre diversos grupos, militares e políticos, simultânea ou alternativamente, na medida em que forem úteis a seu objetivo principal", foi informado ao Itamaraty de Paramaribo. ${ }^{4}$ Acrescentando-se que, naquelas circunstâncias, Bouterse aproximava-se dos pequenos partidos de esquerda - PALU e RVP - e da ala revolucionária das forças armadas - grupo de Sital (SINGH, 2007). Advertindo-se, contudo, que "segundo avaliação generalizada, Bouterse não tem praticamente compromissos ideológicos e utilizará a esquerda na medida de suas ambições e para a consolidação de seu poder pessoal. Não hesitaria ele, também, caso necessário, em atingir duramente os setores de esquerda, sendo sempre possível, por outro lado, que esses setores tentem ultrapassá-lo." 5

Todavia, em 21 de dezembro de 1982, o embaixador Nestor dos Santos Lima foi convocado ao Palácio Presidencial, em qualidade de Decano do corpo diplomático acreditado em Paramaribo, para um encontro com o comandante

1 Nestor dos Santos Lima ao Ministério das Relações Exteriores (no sucessivo MRE), Ofício n. 7 (confidencial), Paramaribo, 10 de janeiro de 1983, Arquivo do Ministério das Relaçôes Exteriores (no sucessivo AHMRE): Rolo 2339.

2 “Até os amigos", Veja, 9 de fevereiro de 1983, p. 33.

3 Cumpre acrescentar que durante os meses de dezembro de 1982 e janeiro de 1983 a embaixada brasileira em Paramaribo concedeu asilo e proteção diplomática e humanitária a vários cidadãos surinamenses que procuraram suas instalações.

4 Osmar Chohfi ao MRE, Telegrama n. 85 (confidencial), Paramaribo, 8 de fevereiro de 1983, AHMRE: Rolo 1531.

5 Ibid. 
Bouterse. Segundo a documentação consultada, após apresentar desculpas por quaisquer inconveniências decorrentes do que ele denominou de "irregularidades" dos dias anteriores, o homem forte do Suriname teria expressado ao diplomata "sua preocupação pela manutenção das relações com o Brasil nos mesmos termos em que vêm sendo levadas a efeito, relações que deseja desenvolver sobretudo em termos de cooperação econômica." Seguidamente, Bouterse teria assegurado que "apesar das 'irregularidades' este país não muda de política externa e manter-se-á dentro dos parâmetros de sua posição de país não-alinhado, como o vem fazendo." ${ }^{\prime}$ Ao manifestar a continuidade da política externa - e evitando uma pronunciada ou definitiva guinada para a esquerda -, provavelmente Bouterse estava tentando esvaziar as crescentes especulações de uma eventual "cubanização" do Suriname, manter a cooperação dos países ocidentais - especialmente da Holanda - e garantir apoio interno de setores moderados. Tudo isso no contexto global e regional da denominada Segunda Guerra Fria (HALLIDAY, 1983; ELY, 1999; GONZALEZ, 1985).

\section{A revolução surinamesa no contexto do conflito Leste-Oeste}

No plano internacional, o massacre de dezembro de 1982 e os acontecimentos subsequentes provocaram a repulsa imediata da maioria dos governos ocidentais com vínculos e interesses no país. Assim, o governo do primeiro-ministro holandês, Rudolphus "Ruud" Lubbers, anunciou a suspensão da ajuda ao desenvolvimento ${ }^{7}$ vital para a economia surinamense -, bem como a cessação de acordos de cooperação militar e policial, cultural, e de assistência diplomática - porém sem chegar ao rompimento das relações diplomáticas. A administração Ronald Reagan, acompanhando as iniciativas holandesas, também manifestou indignação diante da morte de civis sob custódia das forças governamentais, suspendeu a assistência econômica e militar, e anunciou a revisão completa das relações bilaterais. Haia e Washington, junto com as comunidades de surinamenses residentes em ambos os países, também denunciaram a suposta assistência logística, política e ideológica cubana (e soviética) ao regime de Bouterse, aprofundando as divergências entre as partes e colocando a crise do Suriname no contexto do conflito Leste-Oeste (ELY, 1999).

Entretanto, palavras de compressão e alento para o governo de Bouterse foram publicadas e emitidas na imprensa soviética e cubana. Para as agências noticiosas TASS e Prensa Latina, os acontecimentos do Suriname eram resultado de uma estratégia defensiva de um governo progressista e revolucionário diante

6 Ramiro Saraiva Guerreiro à Presidência da República, Informação n. 394 (secreto), Brasília, 23 de dezembro de 1982, Arquivo Nacional: Acervo do Conselho de Segurança Nacional, Caixa 1, D/A.

7 No tratado de Independência, de 1975, a Holanda comprometeu-se a financiar projetos de desenvolvimento econômico e social no Suriname por um montante de US \$1,4 bilhões - isto é, aproximadamente US\$ 100 milhões anuais até 1990 , equivalentes a $10 \%$ do produto por ano. 
das atitudes contrarrevolucionárias dos setores privilegiados do país. Igualmente, voos noturnos com apoio militar cubano foram confirmados após o massacre de dezembro - sem esquecer a continuidade da cooperação militar cubana em termos de cursos de treinamento e segurança. Cumpre acrescentar, fundamentado nas fontes diplomáticas disponíveis no momento, que a embaixada cubana em Paramaribo, então dirigida pelo senhor Oscar Oswaldo Cárdenas - antigo chefe do Departamento do Caribe do Partido Comunista Cubano -, era particularmente ativa na época, contando com o apoio e a simpatia dos militantes do RVP e da ala esquerdista das forças armadas (Badresein Sital, Chas Mijnals, Stanley Joeman). Diante do crescente isolamento perante as potências ocidentais, a alternativa soviético-cubana se tornou plausível, motivando a preocupação do embaixador brasileiro em Paramaribo nos seguintes termos:

A situação criada pela nova fase da ditadura de Bouterse, revelada a partir de dezembro passado, com todas as características de brutalidade comunista, traz o conflito leste-oeste para a fronteira norte do Brasil, o 'soft belly' do Brasil, porta aberta para a discutida área amazônica [...]

Tradicionalmente o Itamaraty guardou com cuidado as informações de que dispõe, uma vez que nada na verdade nos atingia, que não passasse primeiro pelo crivo dos países da linha da frente, USA, UK, etc. Agora o caso já começa a ser diferente. A revolução cubana e a penetração ideológica e física soviética nas lutas paroquiais do continente sul-americano se esboçam nitidamente no horizonte da política externa nacional. O caso do Suriname que até dezembro evoluía sem dar sinais de perigo, subitamente, com a chegada dos "jovens turcos" treinados em Cuba no setor da mobilização social (Joeman e Mijnals) e que por sua vez estão treinando a milícia popular para os trabalhos sujos, abriu uma nova fase de aceleração revolucionária marcada pela violência fria e pela utilização de todo o arsenal teórico que lhes foi transmitido por Havana, direta ou indiretamente. Estamos diante da possibilidade de instalação de um Estado totalitário de esquerda além [da serra limítrofe do] Tumuc-Umac, sem que os meios de comunicação social brasileiros espalhem a nova situação continental. ${ }^{8}$

No Brasil, o golpe preventivo do governo Bouterse contra a oposição foi objeto de constante avaliação e acompanhamento pela própria Presidência da República, pelo Ministério das Relações Exteriores, pelo Exército e pelo Serviço Nacional de Informaçōes - além da imprensa, do Congresso Nacional e de algumas organizaçōes classistas (como a Ordem dos Advogados do Brasil). Como ponderado na citação anterior, as principais preocupações do regime burocrático autoritário brasileiro comandado pelo general João Figueiredo (1979-1985) com relação ao Suriname resultavam de uma complexa combinação de interesses geopolíticos, de segurança nacional e até de projeção hegemônica na região amazônica e especificamente

8 Nestor dos Santos Lima ao MRE, Ofício n. 7 (confidencial), Paramaribo, 10 de janeiro de 1983, AHMRE: Rolo 2339. 
nas Guianas - ainda que a documentação oficial não utilize este último termo. Especificamente existia a preocupação com uma eventual "cubanização" de um país amazônico e fronteiriço, gerada pela ausência de alternativas dentro do bloco ocidental. Desde antes dos episódios de dezembro de 1982, o então chanceler brasileiro Ramiro Saraiva Guerreiro considerava, por exemplo, que:

Politicamente, é inegável nosso interesse na estabilidade política de dois países [Suriname e Guiana] que se limitam com a nossa imensa e despovoada região norte. Ousaria dizer que é uma das poucas áreas em que é vital para o Brasil ter Governos bem dispostos. Não queremos satélites, vassalos, protegidos ou dependentes, mas países autenticamente voltados para seus reais interesses e que não se deixem "instrumentalizar" para fins de outras potências. O estabelecimento de um governo marxista de observância russo-cubana em qualquer um deles forçosamente criaria problemas sérios para o Brasil. Conseqüentemente, o aprofundamento das nossas relaçôes com a Guiana e o Suriname teria um significado político especial; aumentando nossa presença e gerando confiança, constituiria fator estabilizador altamente benéfico à política externa brasileira. Cumpre salientar, aliás, o interesse daqueles países por uma maior integração à América Latina, demonstrado pela decidida participação de ambos no Tratado de Cooperação Amazônica. Cabe-nos corresponder a essa tendência e estimulá-la. O incremento substancial do relacionamento político e comercial do Brasil com a Guiana e o Suriname criaria, ademais, uma ponte para a penetração brasileira no Caribe. $\mathrm{O}$ resultado seria a abertura de uma nova frente na ofensiva comercial brasileira, modesta mas não desprezível, que teria a seu favor a distância relativamente pequena entre os dois mercados. ${ }^{9}$

Gradualmente, a opinião das autoridades brasileiras com relação ao comandante Bouterse passou a reivindicar seu personalismo, pragmatismo e caudilhismo político-militar interessado em preservar o seu poder - e não necessariamente na sua aderência ao marxismo. Em consequência, e para oferecerlhe uma alternativa dentro da comunidade ocidental - nesse caso uma alternativa sul-americana ou especificamente brasileira -, era necessário "atrair" ou cooptar o homem forte daquele país, mediante a intensificação das relações bilaterais e o oferecimento de um pacote de incentivos militares, políticos e econômicos - muitos destes previamente acordados no passado, porém ainda não operacionalizados. Eis a lógica da assim chamada operação Venturini, de abril de 1983.

\section{A missão Venturini e a opção sul-americana para o regime de Bouterse}

Entre 25 e 27 de janeiro de 1982, o chanceler brasileiro Ramiro Saraiva Guerreiro realizou visita de trabalho a Paramaribo. Na ocasião, teve encontros com o então presidente Henck Chin A Sen - que seria derrubado poucos dias

9 Ramiro Saraiva Guerreiro à Presidência da República, Informação n. 143 (secreto), Brasília, 11 de maio de 1981, Arquivo Nacional: Acervo do Conselho de Segurança Nacional, Caixa 1, D/A. 
depois, em 4 de fevereiro -, com o comandante Bouterse e com seu homólogo Harvey Naarendorp. No correspondente relatório de atividades dirigido ao presidente Figueiredo, o chanceler Saraiva Guerreiro manifestou que: "A visita a Paramaribo caracterizou-se pelo claro empenho do Governo surinamense em dar mostras de seu interesse em aprofundar as relações com o Brasil." ${ }^{10}$ Segundo o ministro, "O Governo surinamense atribui ao Brasil papel importante tanto no contexto de seus programas de desenvolvimento quanto no de seus esforços por diversificar as relaçōes internacionais do país, ainda concentradas na Holanda."11 No encontro com Bouterse, de particular interesse para os fins deste artigo, o comandante teria expressado ao diplomata brasileiro a necessidade de reorganização e expansão do exército surinamense, o que requeria assistência técnica e aquisição de armamentos, tendo indicado que "o Suriname está aberto à cooperação com o Brasil nesse sentido." 12 Esse primeiro contato para entendimentos e cooperação na área militar - inclusive com eventual transferência de material de emprego militar de fabricação brasileira - abriu um importante, duradouro e polêmico espectro de atividades e oportunidades de crucial importância na época da missão Venturini e da convergência Figueiredo-Bouterse.

Cumpre acrescentar que, em setembro de 1982, Bouterse visitou pessoalmente Brasília e foi recebido pelo mandatário brasileiro. Ambas as partes exploraram as possibilidades de transferência de armamentos brasileiros para o Suriname, a concessão de assistência técnica e o treinamento de oficiais. Tudo isso com importantes implicações políticas, econômicas e estratégicas nas relações bilaterais.

Dois meses depois da visita de Bouterse, teve lugar o massacre de dezembro de 1982. E, mesmo que o embaixador em Paramaribo condenasse duramente a repressão, a documentação diplomática sugere que a avaliação do chanceler Saraiva Guerreiro foi muito mais pragmática. Certamente levando-se em consideração pressupostos geopolíticos e de segurança nacional especificamente brasileiros, o chanceler informou ao presidente Figueiredo que:

Minha impressão neste momento é a de que Bouterse, tomado por ambições pessoais de poder, não teria necessariamente [sublinhado no original] interesse em voltar-se para Havana. Penso, porém, que pressões mal-calculadas por parte da Haia e de Washington podem deixá-lo sem opções senão a de aproximar-se de Fidel Castro. O panorama é, pois, fluido, desaconselhando juízos apressados. ${ }^{13}$

A mensagem anterior é bastante significativa e relevante. Basicamente, tratavase de evitar que a estratégia do isolamento impulsionada pelos governos da Holanda

10 Ramiro Saraiva Guerreiro à Presidência da República, Informação n. 31 (secreto), Brasília, 8 de fevereiro de 1982, Arquivo Nacional: Acervo do Conselho de Segurança Nacional, Caixa 1, D/A.

11 Ibid.

12 Ibid.

13 Ramiro Saraiva Guerreiro à Presidência da República, Informação n. 394 (secreto), Brasília, 23 de dezembro de 1982, Arquivo Nacional: Acervo do Conselho de Segurança Nacional, Caixa 1, D/A. 
e dos Estados Unidos terminasse empurrando Bouterse definitivamente para o bloco socialista. $\mathrm{O}$ chanceler do governo burocrático autoritário brasileiro acreditava na possibilidade de oferecer ao homem forte do Suriname uma alternativa viável e plausível de apoio e compreensão, inclusive para evitar que o próprio Bouterse terminasse sendo cooptado pela esquerda local.

Saraiva Guerreiro e colaboradores continuaram trabalhando na linha de evitar o isolamento de Paramaribo e para não "jogar o Suriname nos braços de Cuba (e, em última análise, da URSS)." ${ }^{14}$ Após consultas com outras instâncias do executivo e com representantes dos governos da Holanda e dos Estados Unidos, bem como do acompanhamento dos acontecimentos no próprio Suriname, o ministro terminou manifestando, em 26 de janeiro de 1983, que "a melhor opção no momento, é a de atrair [sublinhado no original] o Governo Bouterse por meio de uma rápida intensificação (através de cooperação técnica e outros meios) da presença, no Suriname, dos países que se opõem à influência cubana e soviética." 15 Parece evidente que o argumento é de suma importância e é certamente um antecedente direto da missão Venturini, em abril de 1983.

Paralelamente, entre janeiro e março de 1983, o quadro político do Suriname continuou indefinido. Bouterse, isolado externamente e com baixíssima popularidade doméstica, estava empenhado em preservar-se no poder a qualquer preço. Naquela conjuntura, e diante das pesadas sanções holandesas (e estadunidenses), o homem forte do Suriname tinha basicamente duas alternativas: (i) aproximar-se do Brasil (opção sul-americana), ou (ii) incorporar-se integralmente ao bloco socialista (com eventual risco de terminar sendo ultrapassado e substituído por militantes verdadeiramente marxistas). Afinal, Bouterse decidiu aceitar uma eventual aproximação ao modelo burocrático autoritário brasileiro, que provavelmente lhe permitiria a retomada da cooperação da Holanda e de Washington, além de modernizar as forças armadas e procurar novos parceiros dentro da região latinoamericana.

Em tal sentido, em fevereiro de 1983, o chanceler Harvey Naarendorp visitou Brasília procurando obter a compreensão do governo Figueiredo e buscando a efetivação e a implementação dos acordos de cooperação bilateral identificados desde a época da visita do chanceler Saraiva Guerreiro a Paramaribo, em janeiro de 1982, e especialmente na última reunião mista de cooperação Brasil-Suriname, realizada em Brasília, em novembro de 1982. Ao que parece, Naarendorp também teria outorgado garantias de que o Suriname de Bouterse não se transformaria num ponto de confrontação Leste-Oeste e muito menos em uma fonte de risco ou ameaça à segurança nacional do Brasil na pouco habitada Região Norte do País. Finalmente, o chanceler surinamês teria informado que, diante da estratégia

14 Ramiro Saraiva Guerreiro à Presidência da República, Informação n. 31 (secreto-exclusivo), Brasília, 26 de janeiro de 1983, Arquivo Nacional: Acervo do Conselho de Segurança Nacional, Caixa 1, D/B.

15 Ibid. 
de isolamento impulsionada pela Holanda e pelos Estados Unidos, o governo do Suriname teria decidido reorientar drasticamente suas importaçōes para o mercado brasileiro, o que deveria resultar em um importante incremento das relaçôes econômicas bilaterais - e com significativas consequências políticas. ${ }^{16}$

Segundo a imprensa brasileira, o presidente Figueiredo determinou o envio da missão Venturini ao Suriname em 11 de abril de $1983 .{ }^{17}$ Algumas semanas antes, o chanceler Saraiva Guerreiro tinha determinado a transferência de Washington para Paramaribo do então ministro Luiz Felipe Lampreia. Diplomata em rápida ascensão, Lampreia terminaria sendo chanceler brasileiro no primeiro governo do presidente Fernando Henrique Cardoso (1995-1998). Ainda na capital estadunidense, Lampreia teve contatos com homólogos do Departamento de Estado encarregados da situação surinamesa. ${ }^{18}$ Assim, não parece incorreto supor que a transferência de Lampreia para Paramaribo - onde permaneceria até 1985, primeiro como encarregado de negócios e posteriormente como embaixador - era parte da nova estratégia brasileira para o Suriname.

Foi nesse contexto que o presidente Figueiredo determinou a ida do seu representante pessoal, o general Danilo Venturini, a Paramaribo entre 15 e 17 de abril de 1983. Segundo a imprensa brasileira, a opção de Figueiredo pelo secretáriogeral do Conselho de Segurança Nacional teria sido porque "além de militar e amigo pessoal do presidente brasileiro, Venturini teria muito mais facilidade para firmar acordos - até militares - com Bouterse." ${ }^{19}$ Sabe-se que durante os três dias da visita as partes debateram sobre a evolução das relações bilaterais procurando uma aproximação do Suriname ao Brasil, um afastamento daquele país com relação ao campo socialista, uma eventual recomposição das relações de Paramaribo com Haia e com Washington - inclusive com a facilitação brasileira -, e a eventual moderação de Bouterse na política doméstica.

Segundo o comunicado de imprensa divulgado pelo Itamaraty, na visita do Venturini a Paramaribo "foram examinadas medidas para intensificar as relaçôes existentes entre o Brasil e o Suriname, dentro do quadro dos contatos de alto nível entre os dois países". Seguidamente, a fonte destaca que "Durante as conversaçōes

16 Ramiro Saraiva Guerreiro à Presidência da República, Informação n. 19 (confidencial), Brasília, 18 de janeiro de 1983, Arquivo Nacional: Acervo do Conselho de Segurança Nacional, Caixa 1, D/B.

17 "Antes do fogo no caso líbio, a fumaça do Suriname", Veja, 27 de abril de 1983, p. 42.

18 Ramiro Saraiva Guerreiro à Presidência da República, Informação n. 31 (secreto-exclusivo), Brasília, 26 de janeiro de 1983, Arquivo Nacional: Acervo do Conselho de Segurança Nacional, Caixa 1, D/B. Segundo o documento em apreço, a visita de Lampreia ao Departamento de Estado para tratar a questão do Suriname aconteceu em 24 de janeiro de 1983. Todavia, o diplomata brasileiro teria escutado dos interlocutores que "os EUA consideram Bouterse irrecuperável, impondo-se portanto, neste momento, um trabalho mais no sentido de avaliar alternativas internas ao regime vigente - fora da órbita do Governo surinamense - e prevenir guinadas indesejáveis para a órbita cubano-soviética, do que propriamente criar canais de comunicação com o grupo no poder." Outrossim, "Os interlocutores norte-americanos não chegaram a manifestar que os EUA tencionam agir para depor Bouterse mas tampouco disseram expressamente que os EUA não pretendem atuar no sentido de desestabilizá-lo."

19 "Antes do fogo líbio, a fumaça do Suriname", Veja, 27 de abril de 1983, p. 42. 
mantidas pelo Ministro Venturini e o Comandante-em-Chefe Bouterse, ambos expressaram o desejo dos dois países de preservar a América do Sul de efeitos de confrontações que lhe são estranhas". E que "Neste espírito, concordaram em ampliar e fortalecer a cooperação entre os dois países, com vistas a seu incremento significativo em diversos campos, de acordo com prioridades a ser mutuamente acordadas." 20

A documentação resgatada no Arquivo Nacional sugere que, em princípio, as autoridades de Paramaribo concordaram com a proposta brasileira - ainda que o afastamento do campo socialista não poderia ser imediato ou automático. Em contrapartida, solicitou-se do Brasil, dentre outros itens, a abertura de linhas de crédito para aquisição de material de emprego militar de fabricação brasileira; o incremento das importaçóes de arroz e alumina procedentes do Suriname; o apoio técnico-científico nas áreas de pesquisa mineral, infraestrutura, geração de energia e promoção comercial; e a concessão de bolsas de estudo. Convém acrescentar que a maioria desses acordos tinham sido negociados antes da crise de dezembro de 1982. Em tal sentido tratava-se, na verdade, de operacionalizar entendimentos preexistentes. Mesmo assim, a decisão política brasileira de elevar as relaçôes bilaterais com o Suriname - inclusive assumindo ônus financeiros em uma época de crise econômica no próprio Brasil - era certamente significativa e relevante.

As negociações de alto nível entre representantes de ambos os governos continuaram entre 23 e 25 de maio de 1983, com a visita do primeiro-ministro surinamês Errol Alibux a Brasília. A visita de Alibux foi a primeira missão ao exterior desde sua nomeação pelo comandante Bouterse para assumir a administração pública do Suriname. Ele foi objeto de tratamento privilegiado pelo próprio presidente Figueiredo e pelo chanceler Saraiva Guerreiro - inclusive com discurso presidencial, visita do mandatário brasileiro a recepção na embaixada do Suriname em Brasília e assinatura de acordos de cooperação acertados desde a visita de Venturini a Paramaribo. Nesse contexto, Figueiredo chegou a manifestar que "o potencial humano e de recursos naturais do Suriname e do Brasil, assim como a firme determinação política de nossos Governos, condições essenciais para que ser exploradas amplas perspectivas de incremento da cooperação bilateral”. Também que "com esse espírito, que o Brasil deseja, sincera e fraternalmente, que o Suriname alicerce, seguramente, no contexto de crescente aproximação e harmonia com seus vizinhos sul-americanos, o seu progresso, seu bem-estar e a afirmação de sua personalidade nacional. O Brasil estará sempre disposto a prestar ao país vizinho e amigo, em tudo o que lhe for possível, a sua colaboração franca e eficaz"21.

20 "Comunicado do Itamaraty à imprensa, divulgado em Brasília, em 18 de abril de 1983", Resenha de Politica Exterior do Brasil, n. 37, 1983, p. 131.

21 "Discursos do Presidente João Figueiredo e do Primeiro-Ministro e Ministro das Relaçôes Exteriores do Suriname, Errol Alibux (Tradução não oficial), no Palácio do Itamaraty, em Brasília, em 24 de maio de 1983, por ocasião de almoço oferecido ao representante do Governo surinamense", Resenha de Política Exterior do Brasil, n. 37, 1983, p. 69-71. 
$\mathrm{Na}$ sua intervenção, Alibux manifestou que o fato de ter escolhido Brasília como seu primeiro destino internacional "atesta a importância que nós atribuímos ao nosso relacionamento com o Brasil". Constatando seguidamente que "do mesmo modo, o Brasil também deu expressão a este seu desejo de aprofundar uma compreensão e laços mútuos, quando recentemente tivemos a grande honra de dar as boas-vindas em nosso país ao General Venturini”. Todavia, manifestou sua expectativa de "que os esforços conjuntos dos nossos dois países possam ser dirigidos para o estabelecimento de um relacionamento profundo e duradouro, relacionamento este para o beneficio mútuo e que isso vem assegurando um desenvolvimento sólido e irreversível."22

Nessa mesma linha, no correspondente comunicado à imprensa, as partes concordaram na determinação política de aprofundar as relações bilaterais. Igualmente "reiteraram o desejo de ambos os países de manter a América do Sul alheia a confrontaçôes que lhe sejam estranhas." ${ }^{23} \mathrm{E}$ "salientaram a relevância da intensificação dos vínculos econômicos e comerciais, bem como da cooperação cultural, técnica e científico-técnica entre o dois países." ${ }^{24}$

Naturalmente, a bem sucedida visita de Alibux e sua comitiva ao Brasil reforçou a linha pró-brasileira dentro do governo surinamense. Em tal sentido, o embaixador brasileiro em Paramaribo informou ao Itamaraty o seguinte: "Fui ao aeroporto receber a missão Alibux de regresso do Brasil. Estava presente o Cel. Bouterse e o clima era de alegria generalizada deixando a impressão de que se tratou de um êxito da política externa deste país, e foi isso que me confirmou Alibux propriamente." 25

\section{A missão Venturini e seus críticos: algumas reações diante da convergência Figueiredo-Bouterse}

Diferentemente do que se pode observar na maior parte da literatura brasileira alusiva à missão Venturini, a convergência Figueiredo-Bouterse não significou um imediato, automático ou definitivo afastamento entre Paramaribo e Havana. Na verdade, a documentação consultada permite constatar o surgimento de um período de silenciosa competição entre as linhas pró-brasileira (Alibux e PALU) e pró-cubana (Sital e RVP), erigindo-se o comandante Bouterse em um virtual árbitro da decisão final. Sintomaticamente, durante o mesmo período das negociações para implementar os acordos alcançados com o Brasil, uma importante

22 Ibid.

23 "Comunicado de imprensa Brasil-Suriname, divulgado em Brasília, em 25 de maio de 1983, ao final da visita do Primeiro-Ministro e Ministro das Relaçôes Exteriores do Suriname, Errol Alibux", Resenha de Política Exterior do Brasil, n. 37, 1983, p. 72-73.

24 Ibid.

25 Nestor dos Santos Lima ao MRE, Telegrama n. 394 (confidencial), Paramaribo, 26 de maio de 1983, AHMRE: Rolo 1531. 
delegação cubana - liderada pelo instigante embaixador Oscar Oswaldo Cárdenas impulsionava acordos paralelos com a ilha. Diferentes documentos enviados ao Itamaraty comentavam com apreensão "o clima de competição que Havana pretende propor a Paramaribo em relação à alternativa brasileira." ${ }^{26}$ Mesmo após o afastamento temporário de Sital e Joemans - dois dos mais convictos e articulados representantes da linha pró-cubana no seio do governo de Bouterse, e que para os diplomatas brasileiros poderia "significar um avanço da postura pró-brasileira deste Governo" 27 -, o clima de competição entre ambas as frações continuou pelo menos até a invasão dos Estados Unidos a Granada, em 25 de outubro de 1983 (DOMÍNGUEZ AVILA, 2008). Com efeito, em horas da noite do mesmo dia da invasão da ilha-Estado, o comandante Bouterse expressou em cadeia nacional o seguinte:

A liderança da revolução surinamesa está convicta de que uma repetição dos catastróficos acontecimentos em Granada tem que ser evitada firmemente, quando e onde quer que seja, e se vê obrigada a estabelecer uma investigação escrupulosa de todos os fatores, no âmbito da nossa revolução, que possam a curto ou longo prazo levar a uma polarização irreconciliável nos seus componentes e estruturas, tal como ocorreu em Granada - caso contrário pode ser impedido o progresso da nossa revolução. ${ }^{28}$

Concretamente, Bouterse determinou a saída do embaixador Cárdenas, o rebaixamento do nível das representações diplomáticas nos dois países a Encarregado de Negócios, e a revisão de todos os acordos assinados entre ambos os países - além do retorno imediato dos estudantes surinamenses em Cuba. A reação cubana terminou sendo igualmente fulminante ao decidir retirar não somente o embaixador, mas toda a representação diplomática e, de fato, suspender temporariamente os vínculos com Paramaribo. ${ }^{29}$

Assim, parece evidente que foi o temor de Bouterse diante de uma eventual invasão estadunidense (ou holandesa), e não necessariamente a missão Venturini, o que determinou o rompimento das relações diplomáticas e o brusco afastamento dos cubanos. Ao mesmo tempo, parece importante destacar que a convergência Figueiredo-Bouterse, mesmo que benéfica em termos imediatos ou sob a perspectiva dos conflitos Leste-Oeste, também suscitou críticas, ceticismo e, em alguns casos, rejeição de parte de outros atores com vínculos e interesses na questão surinamesa.

26 Nestor dos Santos Lima ao MRE, Telegrama n. 318 (confidencial), Paramaribo, 17 de maio de 1983, AHMRE: Rolo 1531.

27 Ilegível ao MRE, Telegrama n. 394 (confidencial), Paramaribo, 9 de junho de 1983, AHMRE: Rolo 1531. Nos primeiros dias do mês de junho de 1983, o sargento Sital foi enviado temporariamente para Havana, retornando a Paramaribo em meados de 1984. Cumpre acrescentar que Bouterse estava preocupado com a criação das milícias populares - responsabilidade de Sital, então ministro da Mobilização Social e Juventude.

28 "Declaração do Governo do Suriname com Relação à Crise em Granada", Paramaribo, 25 de outubro de 1983, Arquivo Nacional: Acervo do Conselho de Segurança Nacional, Caixa 1, D/B.

29 “'Doutrina Reagan' surte seu primeiro efeito", Veja, 2 de novembro de 1983, p. 42. 
Para os fins deste artigo é suficiente explorar algumas das reações mais marcantes dos seguintes atores: (i) da oposição democrática surinamesa aglutinada no chamado Conselho de Libertação do Suriname; (ii) do governo holandês, liderado pelo primeiro-ministro Rudolphus "Ruud" Lubbers; (iii) da administração Reagan; e (iv) da oposição política doméstica no próprio Brasil.

No que diz respeito ao Conselho de Libertação do Suriname (CLS), convém mencionar que este foi fundado em 8 de janeiro de 1983, em Amsterdā, por surinamenses residentes ou asilados no exterior - especialmente na Holanda, nos Estados Unidos e nas Antilhas Holandesas -, todos eles opositores a Bouterse, e com objetivo de "libertar" o Suriname do regime autoritário e reinstalar a democracia parlamentarista no país. O ex-premier Henck Chin A Sen foi nomeado como presidente da oposição democrática a Bouterse e imediatamente começou a agir procurando organizar a resistência pacífica e armada - neste último caso com velado apoio dos franceses, dos estadunidenses e dos holandeses - e conseguir reconhecimento doméstico e internacional. ${ }^{30}$ Concretamente, os representantes do Conselho de Libertação do Suriname questionaram os desdobramentos da missão Venturini em função do fortalecimento das capacidades político-militares do regime de Bouterse no contexto da luta interna pela abertura democrática no país. E assim manifestaram ao embaixador do Brasil em Paramaribo:

Dois importantes membros da comunidade indiana me fizeram conhecer a preocupação geral da oposição pelas notícias do fornecimento de armas brasileiras ao Suriname, que está sendo entendida como destinadas apenas a fortalecer a capacidade defensiva deste Governo ante o próprio povo surinamês, posto que não há ameaça externa. Teme a oposição que a abertura brasileira não tenha imposto condiçôes a este Governo, como o deram a entender seus porta-vozes até agora. E nesse caso, o Brasil simplesmente estaria ajudando a oprimir o povo deste país, com as conseqüências eventuais, no caso do desmonte da ditadura de Bouterse. Assegurei a ambos que o fornecimento de armas a este Governo era objeto da maior atenção do Governo brasileiro quanto aos aspectos políticos implícitos na mesma. Fui informado por um dos meus interlocutores [...] que a compra de armas no Brasil combinada com o treinamento da milícia popular já iniciado para ser armada com essas mesmas armas, [coloca] em regime de urgência a reconhecida necessidade de uma ação da oposição que para tanto está preparada com vistas a derrotar este Governo antes da entrega das armas brasileiras, após o que será mais difícil fazê-la com êxito. Ademais, a abertura estaria tendo impacto negativo no prestígio e na força do Comitê de Libertação do Suriname presidido por Chin A Sen, o que torna mais urgente uma ação positiva da oposiçãa. ${ }^{31}$

30 Nestor dos Santos Lima ao MRE, Ofício n. 5 (confidencial), Paramaribo, 11 de janeiro de 1983, AHMRE: Rolo 1186.

31 Nestor dos Santos Lima ao MRE, Telegrama n. 382 (confidencial), Paramaribo, 7 de junho de 1983, AHMRE: Rolo 1531. 
Ainda que a oposição surinamesa agrupada no CLS não lograsse nunca a derrubada do governo do comandante Bouterse, a vinculação do Brasil com o líder máximo da revolução terminou criando desconfortos na sociedade civil daquele país e algumas marcas na política externa brasileira - especialmente após a transição democrática no Brasil.

A posição holandesa diante da missão Venturini e acontecimentos subsequentes era, em certa medida, comparável à do Conselho de Libertação do Suriname. Ainda que contrários à alegada "cubanização" do país amazônico, os holandeses consideraram que a missão Venturini poderia terminar fortalecendo Bouterse e enfraquecendo a estratégia do isolamento. Entrementes, convém acrescentar que a Holanda terminou condicionando a retomada da vital cooperação para o desenvolvimento à saída do comandante Bouterse do poder, ao esclarecimento do massacre de dezembro de 1982, e à redemocratização efetiva do país (KRUIJT \& HOOGBERGEN, 2004). Além disso, parece importante acrescentar que algumas fontes consultadas sugeriam a possível existência de certo ressentimento ou preocupação geopolítica diante da "perda" do Suriname em benefício da presunção de hegemonia brasileira na bacia amazônica, em geral, e na região das Guianas, em particular. Observe-se, por exemplo, que, em junho de 1983, o premier Alibux teria manifestado em seminário com todos os embaixadores surinamenses que "o único país que apóia o Suriname é o Brasil e o único inimigo é a Holanda”32. Nessa linha, o primeiro-ministro holandês Rudolphus "Ruud" Lubbers, em oportuna visita ao Brasil, realizada em maio de 1983 - isto é, um mês após a missão Venturini -, recomendou ao governo brasileiro tentar ser "prudent in selling arms to Suriname and, if possible, to limit quantities" (citado por ELY, 1999, p. 157). Mesmo que nos documentos oficiais publicados com motivo da visita de Lubbers ao Brasil as divergências bilaterais com relação ao Suriname terminaram sendo virtualmente mascaradas ${ }^{33}$, o tema continuou sendo relevante até inícios da década de 1990 (DOMÍNGUEZ AVILA, 2009). De um lado, Brasília apoiando Bouterse; de outro, Haia (e Washington e, posteriormente, Paris) tentando implementar uma estratégia de isolamento de Bouterse e, veladamente, apoiando o Conselho de Libertação do Suriname para derrubar o governo de Paramaribo.

No contexto global da Segunda Guerra Fria, a reação da administração Reagan diante da missão Venturini foi, de modo geral, positiva - ainda que Washington mantivesse sua própria estratégia política-militar de desestabilização e eventual substituição de Bouterse. Inicialmente, a imprensa brasileira noticiou que "ao saber [que seria o general Venturini quem] chefiaria a missão, composta por dois outros militares e dois diplomatas, o governo americano não escondeu

32 Nestor Santos Lima ao Ministério das Relações Exteriores, Telegrama 392 (confidencial), Paramaribo, 6 de junho de 1983, AHMRE: Rolo 1531.

33 "Discurso do Presidente João Figueiredo, no Palácio do Itamaraty, em Brasília, em 30 de maio de 1983, por ocasião do jantar oferecido ao Primeiro-Ministro dos Países Baixos, Ruud Lubbers", Resenha de Política Exterior do Brasil, n. 37, 1983, p. 89-91. 
que gostou da escolha feita por Figueiredo." 34 Vários autores que publicaram sobre o tema em questão coincidem em identificar a possível existência de um virtual consenso estratégico anticomunista compartilhado entre Washington e Brasília. MacDonald (1988, p. 118-119) afirma que "US concerns in Suriname are primarily strategic, not economic", e que "In a sense, US national security interests were well served by Brazilian involvement in Suriname's affairs." Ely (1999, p. 158) sugere que "Washington seemed content to watch Brazil play the role of a benign big brother to its smaller and occasionally wayward neighbors." E Lynch (1983, p. 10) constatou que "Brazilian National Security Adviser Danilo Venturini recently offered Bouterse unlimited credit, military training in Brazil for his troops, the purchase of half of Suriname's rice exports, and a ban on Surinamese exile activity in Brazil, in return for a pledge to stop more Cubans from entering Suriname and perhaps for throwing out those already present." Na parte final do seu instigante e maniqueísta artigo, Lynch recomendava que "The U.S. also should continue improving relations with Brazil. Both want to keep Soviet and Cuban influence out of South America. Brazil may be able to do this using the carrot rather than the stick. If this does not work, the U.S. must be able to work with Brazil on other measures." Outrossim, "U.S. aid to Suriname should be resumed only when democracy is restored. This is the Dutch policy and it reflects a desire beyond the mere exclusion of Cuba from the area".

Ainda reconhecendo a convergência anticomunista de ambas as potências na região amazônica, parece importante verificar algumas divergências tácticas, especialmente no que diz respeito à permanência - ou não - de Bouterse no poder. Acontece que Brasília era contrária à presença cubana no Suriname, porém não necessariamente contrária ao regime de Bouterse. Em contraste, Washington acompanhando as posturas holandesas e do CLS - era contrário tanto à assim chamada "cubanização" do Suriname quanto à continuidade do comandante Bouterse no poder. E uma vez logrado o primeiro objetivo comum - isto é, a "descubanização" do Suriname após o fechamento da embaixada cubana em Paramaribo - o Brasil se encontrou na incômoda posição de ter de sustentar política, militar e até financeiramente o impopular regime predominante em Paramaribo. Entretanto, certas agências do governo dos Estados Unidos, seguramente inspiradas na denominada doutrina Reagan, continuaram apoiando o Conselho de Libertação do Suriname e tentativas de golpe, de invasão guerrilheiro-mercenária e de insurgência contrarrevolucionária - isto é, a denominada estratégia dos conflitos de baixa intensidade (GLEIJESES, 1986).

Com efeito, a recusa de Haia e Washington a uma eventual reconciliação com Bouterse após a "descubanização" do Suriname colocou um importante dilema para as autoridades brasileiras: continuar apoiando o governo Bouterse ou afastar-se deste - com o risco de que o comandante, para sobreviver politicamente, e diante dos limitados recursos financeiros que o Brasil poderia oferecer-lhe, opte

34 "Antes do fogo líbio, a fumaça do Suriname", Veja, 27 de abril de 1983, p. 42. 
por uma reaproximação ao bloco socialista (ou à Líbia), colocando novamente a questão do Suriname no plano dos conflitos Leste-Oeste. Nesse contexto, parece até razoável que documento do Conselho de Segurança Nacional do Brasil, de dezembro de 1983, expressasse que:

Diante dos sentimentos prevalecentes até agora em Washington e Haia, cujas repercussões tendem a dificultar a estabilização do Suriname, é provável ter chegado o momento para intensificar esforços juntos àquelas capitais no sentido de, pelo menos, atenuarem os sinais de animosidade em relação ao Governo Bouterse. Disto poderá depender, não só uma transição tranqüila daquele país para um estágio mais democrático, mas também a credibilidade do Brasil que, em função do seu exclusivo interesse nacional, tanto empenho tem demonstrado nessa direção. ${ }^{35}$

Finalmente, a missão Venturini também provocou reações na própria sociedade brasileira, particularmente no debate parlamentar. Resumidamente, a oposição ao governo Figueiredo atacou a aparente perda de influência política do Itamaraty no seio do governo burocrático autoritário brasileiro devido à determinação do governante de enviar um militar - e não um diplomata de carreira - para realizar a sensível missão em Paramaribo. Igualmente se comentou com apreensão uma eventual subordinação da política brasileira aos interesses estratégicos de Washington na sensível região amazônica. Nessa linha, o Diário do Congresso Nacional, de 26 de abril de 1983, registra um importante e acalorado debate sobre a missão Venturini e desdobramentos imediatos travado principalmente entre os deputados federais Amaral Netto (líder do Partido Democrático Social, representante do Estado do Rio de Janeiro e de orientação governista) e João Herrmann (líder do Partido do Movimento Democrático Brasileiro, representante do Estado de São Paulo e de orientação oposicionista) tudo isso no contexto geral da transição democrática no Brasil. Na ocasião, o líder da oposição na Câmara manifestou o seguinte:

É neste momento que o PMDB quer colocar a sua posição, para que a linha brasileira de autonomia até este instante mantida não sucumba à linha da dependência [...] Queremos saber qual a linha de política [externa] vigente: se a oficial, do Itamaraty, conduzida pelo Ministro Saraiva Guerreiro; se a linha intervencionista da força-tarefa do General Venturini; ou se a linha de dependência econômica preconizada pelo Ministro Delfim. Queremos saber se a linha de não-intervenção do Brasil, até hoje adotada, vai-se manifestar em relação ao Suriname, através do General Venturini, ou através de uma reclamação democrática e diplomática do Itamaraty. ${ }^{36}$

35 Secretaria-Geral do Conselho de Segurança Nacional, Informação n. 003/6a.SC/83 (secreto), Brasília, 6 de dezembro de 1983, Arquivo Nacional: Acervo do Conselho de Segurança Nacional, Caixa 01-E, vol. E.

36 João Herrmann, "Discurso na Câmara dos Deputados", Diário do Congresso Nacional, Seção I, Brasília, 26 de janeiro de 1983, p. 2258. 
$\mathrm{Na}$ réplica, o deputado governista rejeitou a suposta militarização da política externa brasileira ou a subordinação da diplomacia do Itamaraty aos interesses estratégicos dos Estados Unidos no contexto do conflito Leste-Oeste. Amaral Netto acrescentou que "o Suriname é um País pequeno mas de grande importância para a defesa da América do Sul, é um País que deve ser respeitado na sua autonomia e que não devemos, em hipótese nenhuma, não só tentar uma hegemonia sobre ele, como devemos impedir que outros o façam". E, especificamente, sobre a missão Venturini, o deputado apontou:

Creio que é praxe internacional que em determinadas missões, quando a elas se quer emprestar determinado objetivo quase de referência de um chefe de nação, incumbe-se alguém muito ligado a ele e ligado à segurança do país que o manda, para, com o consentimento, aprovação e delegação do Ministério do Exterior, representar o Brasil junto a uma nação que tem problemas sérios.

E o Ministro Venturini saiu daqui levando no bolso uma carta do Ministro Saraiva Guerreiro ao Presidente do Suriname, ou seja, saiu daqui com concordância absoluta e o aval do Ministro do Exterior, para dar força a uma missão que ele, por sua proximidade de amizade junto ao Presidente da República, e de posição de Secretário do Conselho de Segurança Nacional, daria ao Presidente do Suriname uma segurança maior e mais íntima daquilo que se ia dizer.

E o que nós garantimos ao Suriname, Srs. Deputados, foi que, em hipótese alguma, o Brasil admitirá que o seu território sirva de caminho para qualquer movimento contra autoridades surinamenses.

[...] O poder exercido no Suriname é um poder legítimo ou ilegítimo para seu povo, mas, na representação internacional, é o único interlocutor com quem podemos manter relacionamento. E nós consideramos que há um erro na política americana de isolamento do Suriname, como há um erro na política holandesa, quando isso só faz que o Suriname possa se aproximar obrigatoriamente da órbita soviética. ${ }^{37}$

Seguidamente, o líder governista na Câmara garantiu a continuidade da política externa brasileira e a própria confiança do presidente Figueiredo no seu chanceler. E finalmente comentou que, após seu retorno de Paramaribo, o general Venturini teria entregado ao embaixador estadunidense em Brasília um relatório e uma advertência do governo brasileiro ao governo dos Estados Unidos no sentido de sustar eventuais manobras e exercícios militares nas proximidades do continente sul-americano, já que tais manobras de intimidação "poderiam criar problemas para todos nós." 38

Mesmo com tais esclarecimentos, o deputado Herrmann perguntou: "Estão em perigo nossas fronteiras devido ao Suriname?” Questionou, novamente, o fato

37 Amaral Netto, "Discurso na Câmara dos Deputados", Diário do Congresso Nacional, Seção I, Brasília, 26 de janeiro de 1983, p. 2260.

38 Ibid. 
de "dizer que o Gen. Danilo Venturini garante a política de não-intervenção, quando deveria o Ministro Saraiva Guerreiro fazê-lo." E insistiu na necessidade de pressionar o governo brasileiro para manter o principio da não intervenção nos assuntos internos de outros Estados, inclusive para ter condições morais de continuar questionando o intervencionismo norte-americano na América Central (Nicarágua, El Salvador) e no Caribe (Suriname, Granada, Cuba) ${ }^{39}$.

\section{Considerações finais}

Parece evidente que a missão Venturini foi importante - ainda que não necessariamente decisiva - para lograr o afastamento dos cubanos do Suriname e conseguir uma sensível - ainda que breve - aproximação de Paramaribo com Brasília. O ponto mais alto da convergência bilateral aconteceu em 25 de novembro de 1983, com a designação de uma delegação especial brasileira para comparecer às solenidades do Dia da República e do lançamento do Movimento 25 de Fevereiro atualmente denominado Partido Democrático Nacional e plataforma política de Bouterse e seguidores - em Paramaribo. A delegação brasileira foi encabeçada pelo embaixador Marcos Azambuja. O evento em questão era importante na tentativa de Bouterse por institucionalizar - ou "mexicanizar" - o processo revolucionário do Suriname (BRANA-SHUTE, 1986). ${ }^{40}$ Sob o lema de "União na produção e na luta", o evento parece haver logrado atingir seus objetivos mais imediatos - isto é, tentar uma guinada para o centro do espectro político, procurando uma eventual reconciliação com Haia, inclusive para lograr a restituição da valiosa cooperação para o desenvolvimento pactuada no tratado de independência e suspensa após o massacre de dezembro de 1982.

Convém acrescentar que, em encontro particular com a delegação brasileira, o embaixador Azambuja entregou ao comandante Bouterse uma carta remetida pelo general Venturini, onde se manifestou, dentre outros assuntos, que "o sentimento que nos dominou, ao partirmos do Suriname para o Brasil, certamente se materializou em firme e reciprocamente vantajosa cooperação entre os nossos dois países." ${ }^{11}$ As partes também avaliaram a evolução recente das relações bilaterais. Segundo o correspondente relatório de Azambuja para o chanceler Saraiva Guerreiro, o comandante Bouterse teria manifestado sua satisfação com a

39 João Herrmann, “Aparte a Discurso na Câmara dos Deputados”, Diário do Congresso Nacional, Seção I, Brasília, 26 de janeiro de 1983, p. 2260-2261.

40 Dez dias antes das solenidades supracitadas o embaixador brasileiro em Paramaribo comentou que "Bouterse parece progredir no sentido de sua aceitação pelo povo surinamense." Também que "O respaldo popular ao movimento revolucionário representaria sua institucionalização.” Finalmente, e ainda que a frase seguinte deva ser apreciada com certo ceticismo, Lampreia ponderava que "O rompimento com Cuba, muito bem recebido pela população, certamente contribuiu para fortalecer a imagem do regime, agora livre das suspeitas de socialização da economia e inserção no bloco soviético - fantasmas que atemorizavam os surinamenses" (Luiz Felipe Lampreia ao MRE, Telegrama n. 794 (confidencial), Paramaribo, 16 de novembro de 1983, AHMRE: Rolo 1531).

41 Danilo Venturini a Desiré Bouterse, Correspondência privada, Brasília, 25 de novembro de 1983, Arquivo Nacional: Acervo do Conselho de Segurança Nacional, Caixa 1, D/B. 
qualidade do relacionamento alcançado, após a missão Venturini, com o Brasil. Também teria reconhecido a atuação do embaixador Lampreia, o desimpedimento burocrático na aproximação bilateral, e "sua percepção de que o Suriname e o Brasil vêem muitos dos problemas mundiais de uma mesma ótica e com significativas identidades" - comentário particularmente relevante sob a perspectiva do conflito Leste-Oeste vigente naquela época. Finalmente, Azambuja acrescentou como avaliação geral da visita a Paramaribo o seguinte:

De todos [os interlocutores] ficou-me a clara impressão da importância de nossa presença no Suriname, da relevância e da oportunidade da missão com que [Vossa Excelência Ministro Saraiva Guerreiro] me honrou e da expressiva realidade que já representa o conjunto de nossas relaçôes com este vizinho. Mais ainda ficou-me a nítida impressão das expectativas criadas em torno de nosso potencial de cooperação e entendimento. ${ }^{42}$

Parece coerente, compreensível e racional que Bouterse manifestasse seu apreço pela posição brasileira de apoiar seu governo quando as outras potências tradicionais com vínculos e interesses no Suriname questionavam sua permanência no poder político. Além disso, é importante verificar que a decisão política de Figueiredo por elevar o patamar das relaçōes bilaterais resultou em um febril dinamismo na cooperação militar, econômica, técnica e política. Em certa forma, Brasília permitiu garantir a sobrevivência e o prestígio do comandante Bouterse até sua "renúncia" ao cargo de chefe das forças armadas surinamesas em meados de 1992 - e, mesmo assim, ele continuou sendo figura política altamente relevante no país, inclusive como eventual candidato presidencial pelo Partido Democrático Nacional no próximo pleito eleitoral marcado para o mês de maio de 2010.

Cumpre acrescentar que, sob a perspectiva do governo brasileiro, a missão Venturini logrou atingir seus objetivos fundamentais, isto é, garantir uma convergência bilateral capacitada para evitar a instalação naquele país do conflito Leste-Oeste - ou uma guinada de Paramaribo para o campo socialista -, preservar a segurança nacional na porosa fronteira norte, implementar um significativo "pacote" de cooperação horizontal (sul-sul), e ampliar a influência e prestígio brasileiro na sensível região amazônica. Para o lado surinamês, e especificamente para o comandante Bouterse, a aproximação com o Brasil foi relevante, porém insuficiente para resolver com tranquilidade as múltiplas tarefas e desafios domésticos e externos - que agoniavam seu regime. Com efeito, a documentação consultada sugere que após 1984 teve uma diminuição gradativa, um "desgaste" e uma virtual "perda de substância" nas relaçôes bilaterais causadas, de um lado, por um certo desapontamento de parte dos dirigentes surinamenses que possivelmente esperavam mais do Brasil - lembrando-se que antes de 1983 a cooperação

42 Marcos Azambuja e Luiz Felipe Lampreia ao MRE, Telegrama n. 821 (confidencial), Paramaribo, 28 de novembro de 1983, AHMRE: Rolo 1531. 
holandesa oferecia quase US\$ 100 milhões anuais a fundo perdido; e, de outro lado, paradoxalmente a extinção da ameaça cubana terminou tirando parte do senso de urgência da cooperação brasileira para aquele país - recordando-se que, na época, o próprio Brasil experimentava os rigores da crise da dívida externa e da assim chamada década economicamente perdida.

\section{Referências bibliográficas}

Fontes primárias:

Arquivo Histórico do Ministério das Relações Exteriores (AHMRE)

Arquivo Nacional - Acervo do Conselho de Segurança Nacional

Diário do Congresso Nacional (Brasília)

Resenha de Política Exterior do Brasil (Brasília)

Revista Veja (São Paulo)

Fontes secundárias:

BRANA-SHUTE, Gary. Back to Barracks? Five years 'Revo' in Suriname. Journal of Interamerican Studies and World Affairs, Vol. 28, No 1, 1986, p. 93-121.

DOMÍNGUEZ AVILA, CARLOS F. Bipolaridad, Autodeterminación y Oposición al Intervencionismo: Granada frente a la Segunda Guerra Fría (1979-1983). Projeto História, N. 36 (junho), 2008, p. 85-101.

. Em Defesa da Democracia e do Interesse Nacional: O Brasil diante do Interregno Kraag no Suriname (1991). Textos \& Debates, V. 14, 2009, no prelo.

ELY, Roland. Brazilian Presence in the Guianas: João VI to João Figueiredo, 1807-1985. Revista Interamericana, Vol. 29, No 4, 1999, p. 145-168.

GLEIJESES, Piero. The Reagan Doctrine and Central America. Current History, Vol. 85, No 515, 1986, p. 401-437.

GONZALEZ, Edward. The Cuban and Soviet Challenge in the Caribbean Basin. Orbis, Vol. 29 No 1, 1985, 73-94.

HALLIDAY, Fred. Cold War in the Caribbean. New Left Review, No 141, 1983, p. 5-22.

KRUIJT, Dirk, e HOOGBERGEN, Win. Surinam, las Antillas Holandesas y los Países Bajos. Foreign Affairs en Español, Vol. 4, № 2, 2004, p. 102-110.

LYNCH, Edward. Bold Action in Grenada: Countering A Soviet Threat. Backgrouder, No 303, 1983, p. 1-12.

MACDONALD, Scott B. Insurrection and Redemocratization in Suriname?: The Ascendancy of the 'Third Path.' Journal of Interamerican Studies and World Affairs, Vol. 30, No 1, 1988, p. 105-132.

SINGH, Chaitram. Reining in the Military: Re-democratization in Suriname. Journal of Third World, Spring, 2007, p. 1-24. 


\section{Resumo}

O artigo aborda a evolução das relações bilaterais entre o Brasil e o Suriname durante a primeira metade da década de 1980, e especificamente o processo de tomada de decisão que culminou com o envio da assim chamada missão Venturini ao Suriname. O texto fundamentase em evidência documental primária resgatada em dois arquivos brasileiros. Conclui-se que os objetivos fundamentais propostos pelo governo brasileiro com relação ao Suriname - então controlado pelo comandante Desiré Delano Bouterse - foram alcançados, particularmente no que diz respeito a evitar a instalação do conflito Leste-Oeste na sensível fronteira norte do país e na região amazônica, em geral.

Palavras-chave: política externa brasileira; Suriname; Região Amazônica; história das relações internacionais do Brasil.

\section{Abstract}

The paper explores the evolution of the bilateral relations between Brazil and Suriname during the 1980s, especially with the so-called Venturini mission to Suriname. The text uses original documents from two Brazilian archives. The article shows that the main goals of Figueiredo's administration with respect to Suriname were fulfilled, especially concerning the avoidance of an East-West conflict in the sensitive north frontier of the country and in the Amazon region.

Keywords: Brazilian foreign policy; Suriname; Amazon Region; Brazilian history of international relations. 